\title{
The Treatment of Varicose Ulcers of the Leg.
}

Henschen (Corresp. Bl. f. Schweiz. Aerate, No. 12, 1914) strongly recommends the following treatment for varicose ulcers of the leg which have begun to granulate in a healthy manner. The limb is first elevated for 15 to 30 minutes and massaged upwards. The skin of the leg is shaved and thoroughly cleansed, and then the ulcer is strapped in the following manner. A series of strips of plaster 4 to $5 \mathrm{~cm}$. wide and one and a half times as long as the diameter of the limb at the ulcer, are applied from below upwards so as to overlap and cover in the ulcer. The plaster is applied by placing the middle of each strip on the back of the limb and crossing the ends over the ulcer, and it is essential that the plaster should be applied very firmly. Each strip should overlap the previous one by two-thirds, and the strapping should extend from well below the ulcer to some distance above it. A few layers of gauze and an ordinary bandage are applied over the plaster. If perforated plaster is used through which discharge can escape, it can be left on for 2 to 4 weeks, the overlying gauze being changed when necessary. The patient follows his usual avocation, and healing goes on steadily under the strapping. Henschen recommends a perforated strapping known as "Klebrobinden" as specially suitable, owing to its being porous, elastic, and unirritating. It is interesting to note that this method is a revival of a plan described, according to Henschen, by Baynton, in London, in 1797.

J. W. S.

\section{OBSTETRICS AND GYNECOLOGY.}

UNDER THE CHARGE OF

A. H. F. BARBOUR, M.D., AND J. W. BALLANTYNE, M.D.

\section{Delivery by Hysterectomy.}

WHEN one speaks of delivery by hysterectomy one thinks naturally of Porro-Cæsarean section or of some of its modern modifications, of the cases of obstructed labour in which the uterus is incised, the child extracted, and the uterus above the cervix removed; but that is not what Casalis and Lecocq (Ann de. gynéc. ét d'ubstét., s. 2, vol. xi., pp. 67-71, 1914) mean when they write of delivery by hysterectomy. They mean quite a novel procedure, namely, the opening of the abdomen in labour and the performing of a total or pan-hysterectomy with the living infant inside the uterus. Casalis assisted Dr. E. Reymond in the carrying out of this operation in the year 1910. These two surgeons performed it a second time in 1912, and Casalis and Lecocq had a third case in 1913. In the first instance, the patient, a woman of 39 years and a iii.-para, suffered from albuminuria and placenta prævia; the os was incompletely dilated, the bleeding became very severe, the pulse uncountable, and the woman's condition extremely dangerous. Dr. Reymond, who had been hastily summoned, opened the abdomen and 
performed a total hysterectomy without previously incising the uterus ; the organ, with the child still inside, was then placed on a plate, opened by one of the assistant surgeons, and the infant extracted alive. The blood-supply of the uterus was secured in the ordinary way by six ligatures, but Reymond was very careful to allow as short a time as possible to elapse between clamping the second uterine artery and completing the vaginal incision which set the uterus free. Both mother and infant did well.

In the second case, a woman of 35, with cancer of the cervix and in labour (premature), the same procedure was carried out with the same happy result. The third patient to undergo this form of Cæsarean section was also 35 years of age ; she was a vi.-para, had given birth to four dead infants, and had a contracted pelvis. She was in labour; the os was fully dilated, the bag of membranes had been ruptured for some time, the lower uterine segment was thinned out, and the uterus was passing into a state of tetanic contraction. Fearing rupture of the uterus if forceps was applied, Casalis and Lecocq performed total hysterectomy and opened the womb after its removal from the body. Both mother and child were saved.

The details of the operation are comparatively simple. A long abdominal incision is made, from three or four finger-breadths below the ensiform cartilage to the symphysis; the pregnant uterus is drawn outside the abdomen; the round ligaments are clamped (or ligatured) and divided, and so also are the broad ligaments; the bladder is dissected off to the front; the left uterine artery is next caught and divided and the vaginal canal opened into; the whole uterus is now ready for removal, save that it is still attached by the base of the right broad ligament and the right uterine artery; so, finally, the right uterine artery is clamped and divided, and the uterus and contents rapidly separated and removed. An assistant is at hand who immediately opens the uterus and takes out the child, resuscitating it if need be. The operator meanwhile puts ligatures on the pedicles and bleeding points, and closes with stitches the vaginal vault and the abdomen. In the second case the time which elapsed from the application of the clamp to the right uterine artery and the opening of the uterus on the plate was only 30 seconds.

Obviously this operation opens up new possibilities in Cæsarean section. It will find its indications in the cases which are generally chosen for the Porro, viz. previous infection of the uterus in contracted pelvis and in other states which forbid delivery per vias naturales, necessity for the removal of a cancerous or a fibromatous pregnant uterus, and the necessity for the removal of a uterus which does not contract but keeps on bleeding. But it is a better operation than the Porro. In the first place, the risks of peritoneal infection are greatly reduced, for the uterus is not opened until it is outside the body and 


\section{Obstetrics and Gynecology}

the field of the operation ; in the second place, the fear of hæmorrhage is much lessened, five, at any rate, of the six pedicles being firmly tied before section; in the third place, in cases of cancer the chances of return of the disease are diminished, because the organ is removed in one piece; and, in the fourth and fifth places, there is rapidity of procedure and simplicity of after-treatment. For the mother, therefore, there is everything to be gained; but what of the child? The best answer is the fact that the child was saved in every one of the three cases. Of course it is taken for granted that the child is alive at the beginning of the intervention; there is then no reason why it should die until the blood-supply of the placenta is cut off. Consequently the tying or clamping of the second uterine artery is left to the very last; immediately it is made secure the operator will lose no time in completing the hysterectomy, and his assistant will make speed to get the child out of the womb. After all, one's experience in Cæsarean section after the death of the mother proves that there is a definite, if short, time during which the infant continues to live after its placental blood-supply has been cut off. One will hear more of Reymond's modification of the Cæsarean section.

\section{Extraordinary Fertility and Menorrhagia.}

Cases of extraordinary fertility are still occasionally met with even in these days of small families; further, the association of great fertility with twin and triplet-bearing has been noted, as has also the fact that both large families and twin-bearing seem to be hereditarily transmitted; but the record of excessive fertility with extraordinary merorrhagia and metrorrhagia given to the obstetrical and gynecological world by Dr. Bruno Berger (Zentralbl. für Gynük., vol. xxxviii. pp. 367371 , 7th March 1914), is surely a most uncommon one. After referring to some amazing examples of fertility, including Boer's case of a man whose first wife had ten times twins, seven times triplets, and four times quadruplets, and whose second spouse had triplets once and twins six times, Berger proceeds to give details of the case observed by himself. The woman was 45 years of age, and a widow. Her mother had six children, including a pair of twins of whom the patient was one ; further, her mother suffered much from menorrhagia. Her sisters, however, had small families and normal menstruation. With regard to the woman herself she began to menstruate when she was 10 years old, and, literally, never stopped bleeding till her marriage at the age of twenty. The day after marriage the bleeding stopped and remained away till four months later, when she miscarried of twins. It ought to be added in connection with this bleeding tendency that ordinary cuts and wounds did not in this woman's case bleed profusely ; it was purely genital hæmorrhage with which she was affected. She bled for a month after the miscarriage, then she became pregnant again 
and had a three months' abortion. She bled for fourteen days, became pregnant again, had a seven months' child which she nursed for a year and bled for a month after its birth, when again she became pregnant and after ten months had a child born by the breech. After fourteen days' bleeding she was pregnant once more, and on this occasion she carried the child to the normal full time.

Up to this time in her married life she had had five pregnancies, including a twin miscarriage, an abortion, a premature labour, a ten months' labour, and a normal labour at full time. But this was only a beginning, as it turned out. After the normal labour she bled for six weeks, then became pregnant and after nine months had twins; she nursed them both as well as the child born on the previous occasion. Fourteen days of hæmorrhage followed, then a fresh pregnancy and a birth at the end of ten months; then a six weeks' bleeding and a normal labour nine months later; then five weeks' bleeding and a triplet abortion at two and a half months; then came two more abortions with bleeding between them; then another pregnancy which was normal and ended in the birth of twins. After the twins she bled profusely for six weeks, and then, a remarkable occurrence for her, for seven whole months she only lost a slight amount of blood every four weeks. Then came another pregnancy and a normal labour.

The woman now contracted a second marriage. A normal pregnancy at once followed, and after it severe bleeding occurred, lasting a year. Then came a two months' abortion, on the night following which she seems to have been impregnated once more and the bleeding stopped instantly. A full-time confinement succeeded, then two more normal pregnancies after hæmorrhagic intervals of four and eight weeks respectively. Some eleven more gestations ensued, with a growing number of abortions (one of twins), and then steady profuse bleeding set in, for which she came to receive treatment. In 25 years she had been pregnant 30 times, and had given birth to 36 children, of whom 20 were alive. There was one triplet and four twin-pregnancies. Of the twenty children born alive nine only survived, five daughters and four sons. The two eldest daughters were married ; they had regular periods, and one of them, who was eighteen years old, had had two normal pregnancies, the other (twenty-two years of age) had had one normal birth.

With regard to the patient's own state, it was found that all her internal organs were normal. She was strong, well-nourished, and somewhat pale. She had a scaphoid shaped scapula. There was slight vaginal prolapse (which was really not to be wondered at), the annexa were normal, and the uterus, of normal size, was in a position of anteflexion. No tumour was to be felt. She refused to come into hospital.

Dr. Berger is of opinion that there is a hereditary element in this case of excessive fertility; the fact that a daughter, not yet 18 years 


\section{Ophthalmology}

old, has had two pregnancies, seems to point to that conclusion. Other interesting things are the fact that the woman herself was a twin, that she had twins and triplets amongst her many pregnancies, and, most interesting of all, that she bled continuously all the times in her reproductive life when she was not pregnant. From her menarché at ten years up to her marriage at twenty she bled without ceasing, and thereafter the hæmorrhage (save during her pregnancies) was continuous with the sole exception of two periods, one between her eighteenth and nineteenth pregnancies and the other (for a few months) in the last year. The history is so extraordinary that it will probably be found to be quite unique. The cause must be regarded as mysterious, but the theory which Dr. Berger advances is a possible one. Beginning with the observations of Hellin and Bumm, to the effect that in women with large families and a tendency to twin-bearing the ovaries show an arrested development, remaining in the fotal state in which there is an immense number of ovisacs present in them, the writer goes forward to the conclusion that this prolific woman has ovaries with this superfluity of ovisacs and that she literally suffers from continuous instead of periodic ovulation. This would serve to account also for the more or less continuous bleeding in the non-pregnant intervals, for as a rule menstruation ceases when ovulation ceases. Certainly the theory of frequent ovulation explains the great fertility and the promptness with which a fresh gestation almost invariably followed a confinement or a miscarriage, and it offers a reasonable explanation of the continuous uterine hæmorrhage. Dr. Berger does not touch directly upon the state of the thyroid gland, and of course nothing can be determined regarding the suprarenal capsules and the pituitary body; but such questions as the calcium-content of the blood could be investigated and might reward research.

J. W. B.

\section{OPHTHALMOLOGY.}

UNDER THE CHARGE OF

W. G. SYM, F.R.C.S., aNd ANGUS MacGILLIVRAY, M.B., B.Sc. THE subject of which the journals dealing with the diseases of the eye are full just now is sclerectomy-trephining of the corneo-sclerotic junction, or "Elliot's operation"-its dangers, its good points, its technique, the indications for its performance, and such matters. Amid much that is still uncertain it does appear clear that in the minds of the majority of those best calculated to form a sound opinion we have been presented with an operation of incalculable value in a certain type of glaucoma, and that its value seems to be greatest precisely in those forms of glaucoma which are likely to benefit least by von Graefe's iridectomy.

In a paper dealing with the subject generally, Professor Sattler (Berl. kin. Woch., 1914, Nos. 49, 50) urges his compatriots to cease the use 